\title{
Organizational Enablers for NPD Portfolio Selection
}

\author{
Jeremy Hutchison-Krupat ${ }^{1} \quad$ Stylianos Kavadias ${ }^{2}$
}

\begin{abstract}
:
Despite substantial research that advocates the "right" portfolio of new product development initiatives for the firm, one important aspect has been overlooked: creating a portfolio of new product development initiatives is not equivalent to choosing from a menu of initiatives. Rather, these initiatives are defined by and within the organization. Thus, portfolio selection rests upon two challenges: the cross-functional nature of collaborative tasks, and the role of explicit and implicit incentives on innovative outcomes. This paper explores how these factors ultimately determine the initiatives an organization pursues. We abstract a new product development organization as two functional managers who report to senior management, and analyze the strategic interactions between all three stakeholders. Senior management decides whether to empower the functional managers to define the initiative, and how to reward them contingent on the outcome. We evaluate how the asymmetry of information regarding each function's capability, and the explicit and implicit rewards and penalties imposed on the functional managers affect the upfront resource allocation. We find a profound effect of the information asymmetry: the set of initiatives the firm deems profitable is reduced, thus impeding the organization's potential to innovate. To counter such a shortcoming, senior management may optimally misalign the objectives of the stakeholders.
\end{abstract}

Keywords: NPD Portfolio, NPD Process, Incentives in Innovation, Tolerance for Failure, Technology Management.

\section{Introduction}

In the early 2000's both Wyeth Pharmaceuticals and GlaxoSmithKline (GSK) set out to restructure their research and development (R\&D) organizations to be more effective. Both firms identified the locus of decision rights-who in the organization makes key decisions-as a fundamental driver of their R\&D organization's effectiveness. Although both firms sought to change the locus of decision rights and the associated incentives, the manner in which they sought to change them differed substantially. Specifically, Wyeth sought to restructure their organization so that resource commitments were determined in a centralized fashion and incentives could be considered more harsh (Huckman et al. 2010). The emphasis was on standardization and control. In contrast, GSK chose to decentralize decision rights, empower managers, and to foster an "entrepreneurial spirit" (Huckman and Strick 2010). Indeed, GSK sought to utilize the specialized knowledge of scientists

\footnotetext{
${ }^{1}$ University of Virginia, Darden School of Business; krupatj@darden.virginia.edu

${ }^{2}$ University of Cambridge, Judge Business School; s.kavadias@jbs.cam.ac.uk
} 
who were closest to the development process. Following Wyeth's restructuring the number of new drug applications declined, subsequently the number of therapeutic areas Wyeth pursued was cut in half, and the next year the firm was acquired by Pfizer ${ }^{3}$. In contrast, when GSK commenced its restructuring they had only two products in late stage development, yet, eight years later they had thirty four drugs and vaccines in late stage development (Garnier 2008, p. 1). Although we cannot draw direct conclusions on the effect the restructuring had on either outcome, still, a valid question remains: what impact could the locus of decision rights, incentives, and the culture of the firm have had on achieving such outcomes?

The story we have presented is not unique: it echoes observations and accounts of typical new product development (NPD) restructuring scenarios that abound in the popular business press and in case studies (Bower 1970, Loch and Mihm 1996, Bower and Gilbert 2005, Garnier 2008, Huckman and Strick 2010, Huckman et al. 2010). Some common explanations for outcomes similar to the one presented lay blame on the individuals, e.g., "managers were too risk averse to meet the firm's innovation objectives" or "managers pursued their own private objectives, which were misaligned with the firm's strategy." True, these explanations may, in fact, be plausible, however, they are exogenous to the product development process itself. They imply the only way to fix the "problem" is to hire new people. We acknowledge these explanations but seek an alternative explanation, one that includes the possibility that the cause of such outcomes could be the structure of the NPD organization itself.

Economic theory has generated a significant stream of literature on agency (see Holmstrom 1982, Grossman and Hart 1983, Aghion and Tirole 1997, Gibbons 2005). The basic insight remains bold and robust: parties that are responsible for the execution of tasks with uncertain outcomes are risk averse; to induce risk-taking behavior, extra pay-for-performance compensation is necessary. However, the reality, as depicted through much of the recent NPD literature, points to strong limitations regarding the application of agency rules. NPD outcomes rely on (complex) interdependent cross-functional information, which is non-verifiable and dispersed among different organizational units (Hauser 1998, Tatikonda and Rosenthal 2000, Mihm et al. 2003, Sosa et al. 2004, Mihm 2010, Schlapp et al. 2015). Moreover, NPD performance critically depends on the manner in which uncer-

\footnotetext{
${ }^{3}$ As Huckman (2010) notes, "it was not clear whether the [restructuring] had any effect on these outcomes in either direction" (p. 13), still the outcome is noteworthy.
} 
tainty and information asymmetry is manifest at different levels in a firm's organizational hierarchy (Sosa et al. 2002, Andersen and Joglekar 2005, Blindenbach-Driessen 2015, Hutchison-Krupat and Kavadias 2014, Hutchison-Krupat 2017).

More recent research explores how the structure of an organization interacts with the product development process, and the NPD portfolio in particular. Anderson and Joglekar (2005) provide a framework that outlines the dynamic role of multiple sources of uncertainty, and how they affect decision making at different levels of an organization's hierarchy. Chao et al. (2009) investigate an organizational hierarchy in which the funding authority, financial incentives, and the implicit incentives (career concerns) affect the NPD portfolio's balance between exploration based and exploitation based initiatives. Thus, in Chao et al.'s (2009) setting, the decisions are made by a single manager who allocates resources between two predetermined initiatives. In contrast, we focus on two collaborative functional managers, who together must decide whether a single initiative should be included in the organization's portfolio.

Manso (2011) also studies the impact of implicit incentives, specifically, the importance of a firm's need to have a temporal tolerance for failure to enable explorative innovation. He argues that some (positive) reward for explorative (radical) efforts that fail, provides incentives for risk-averse agents to pursue such efforts, despite the availability of a less risky alternative. Thus, he justifies the need for a failure-tolerant organization, but does not discuss its implications for the selection of strategic initiatives. Within an experimental setting, Hutchison-Krupat and Chao (2014) study a manager's willingness to allocate resources to an innovative initiative as it relates to the penalty they could incur if they experience a failed initiative. In particular, they evaluate how tolerance for failure and shared decision making interacts with financial penalties and rewards to affect an individual's resource allocation decision on an uncertain NPD initiative. We build on this work to expose the way in which a low tolerance for failure can impact the selection decision, and of equal import, the set of initiatives an organization would even consider viable options to explore.

We develop a principal-multi-agent model to analyze how the collaborative nature of NPD affect the firm's ${ }^{4}$ portfolio decisions. Subsequently, we study how both explicit financial incentives (e.g. bonus plans) and implicit organizational norms (e.g. the tolerance for failure) moderate the portfolio composition. Specifically, we show how different organizational norms either enable

\footnotetext{
${ }^{4}$ We will use the terms senior management, firm and VP interchangeably throughout the paper.
} 
or inhibit senior management to include an initiative in their NPD portfolio. Indeed, we find there is an important NPD-specific analog to Markowitz's (1952) observation that each individual investor's optimal portfolio depends on their risk attitude: the portfolio that each firm is able to pursue depends on the organizational norms and structure of the NPD organization.

Overall, we make a three-fold contribution to the literature: First, on a conceptual basis, we depart from the "traditional" perspective that views the selection decision for an NPD portfolio as a choice from a "menu of initiatives". Instead, we advocate that organizational dynamics play an important role in defining which initiatives are even placed on the menu. Second, we identify that the asymmetry of information regarding the cross-functional capabilities, combined with the strategic interaction across disciplines, may inhibit the organization's ability to pursue risky innovative endeavors. Finally, we discuss the relative efficiency of formal versus informal means by which the organization can affect their limited ability to pursue risky initiatives.

\section{Model}

In this section, we introduce the formal properties of our model. Our focus is on the front-end definition of an NPD initiative.

\subsection{Functions, capabilities, and the initiative}

We consider an organization where senior leadership (the principal) must decide whether or not to pursue an innovative initiative that, if successful, would yield a value $V$ to the firm. Senior leadership's interests are interests are carried out through a VP, e.g., the vice president of R\&D, who oversees two functional managers (the agents), where each function is denoted by the subscript $i \in\{a, b\}$.

Given the innovative nature of the strategic initiative, it only succeeds with probability, $p$. However, this probability itself is not fully understood by all. Naturally, the functional managers, those who execute the detailed tasks, have a better understanding of task-specific knowledge and the inherent risks associated with their specific function. Yet, even their knowledge of $p$ has limitations. First, they may only be able to understand the specific details associated with their own respective function. Second, even if they were to possess both function's information, there 
would still exist some fundamental uncertainty associated with the overall initiative. Indeed, not even full information allows the functional managers (or senior management) to know $p$, the exact probability the initiative has to eventually succeed.

What is known is that the initiative's exact probability of success, $p$ is drawn from a beta distribution $f$. We assume the risk profile, $f$, depends on two key factors: i) the resources each function commits to the initiative, $e_{i}$, and ii) each function's capability, $\eta_{i}$. More specifically, $p \sim \operatorname{Beta}\left(\alpha_{a}, \alpha_{b}\right)$, where $\alpha_{a}=\eta_{a} e_{a}$ and $\alpha_{b}=\left(\eta_{b} e_{b}\right)^{-1}$. As such, $f\left(p ; \alpha_{a}, \alpha_{b}\right)=\left(p^{\alpha_{a}-1}(1-\right.$ $\left.p)^{\alpha_{b}-1}\right)\left(\int_{0}^{1} u^{\alpha_{a}-1}(1-u)^{\alpha_{b}-1} d u\right)^{-1}$, and the expected probability the initiative succeeds, $E[p]=$ $\frac{e_{a} \eta_{a} e_{b} \eta_{b}}{1+e_{a} \eta_{a} e_{b} \eta_{b}}$. Note, that this specific functional form captures a key intuitive property, despite the ambiguity associated with the new initiative's probability of success: the likelihood that the initiative has a high probability of success increases in each function's resource commitment and in each function's capability.

More specifically, each function's capability, $\eta_{i}$, parameterizes how hard it is for that function to "move the needle" on the initiative's likelihood of success. That is, we can think of $\eta_{i} e_{i}$ as the effectiveness of a function, such that a higher $\eta_{i}$ makes each unit of effort that much more effective. More importantly, though, is the combined capability of both functions, as captured through $N=\eta_{a} \eta_{b}$, which ultimately determines to what degree the organization can move the needle on the likelihood of success. When the combined capability is higher, the likelihood that the initiative succeeds increases to a greater degree for each unit of resources as compared to an organization where the combined capability is lower. Said differently, when the organization's capability for an initiative is high, less resources are required to have a high likelihood of success. In contrast, when the combined capability is low, the organization may exert substantial resources and still struggle to succeed.

The VP knows each function's capability follows a Bernoulli distribution $g\left(\eta_{i}\right)$ with equal mass placed on the probability a function possesses a high or low capability. For ease of exposition, we assume the functions' capabilities are symmetrically distributed. Again, what matters is the distribution of the combined capability. Thus, each function is equally likely to realize either a high capability, $\eta_{i}=h$, or a low capability, $\eta_{i}=\ell$, where $0<\ell<h$. Although, on expectation, each function is equally capable, each function's realized capability could differ. Thus, each function's mean capability, $E\left[\eta_{i}\right]=\mu=\frac{h+\ell}{2}$, and the coefficient of variation for each function's capability is 
$c v=\frac{h-\ell}{h+\ell}$. These two metrics are important because, ex-ante, the expected capability reflects the degree to which the firm can increase their chances of success, and the coefficient of variation serves as a proxy for the degree of asymmetry in the organization. Indeed, a low coefficient of variation implies each function's capability is fairly well understood.

In summary, our model formulation captures the following NPD process properties:

- It is impossible for either functional manager to fully compensate for the other stakeholders' lack of capability or resource commitment.

- It is impossible to ex-post decouple the exact contribution of either manager to the success or failure of an initiative.

- Even with significant investment of resources, there is always some level of residual risk that represents the nature of innovation.

- There may exist a certain level of asymmetry of information among the stakeholders.

\subsection{The implications of a successful, and failed, initiative}

If the outcome of the initiative is successful, it yields the full opportunity $V$ to the firm, while a failed initiative yields no revenue at all. Independent of the outcome, however, the firm incurs the total cost of the resources committed by both managers. Thus, when the initiative succeeds the firm's total profit is ${ }^{5}: \Pi \mid$ success $=V-\sum_{i=\{a, b\}} e_{i}$; and when the initiative fails the total profit is $\Pi \mid$ failure $=\Pi_{f}=-\sum_{i=\{a, b\}} e_{i}$.

Given the inherent uncertainty of the initiative, traditional agency theory would command that senior leadership provides financial incentives to the functional managers, to induce them to undertake the initiative. Thus, the VP may offer a simple pay-for-performance scheme in the form of a linear contract $w_{i}+k_{1} \Pi_{s}$, where $w_{i}$ represents the fixed wage portion of the contract and $k_{1}$ represents the share of the profits the VP offers to either functional manager. It follows, that the VP, who acts as a proxy for the firm, has utility: $U_{f}(\cdot) \mid$ success $=\left(1-2 k_{1}\right)\left(\Pi_{s}\right)$ and $U_{f}(\cdot) \mid$ failure $=\left(\Pi_{f}\right)$.

The natural question, though, is what consequences do the managers face when the initiative fails? In reality managers may experience different treatment following a failed initiative as opposed

\footnotetext{
${ }^{5}$ We adopt the following notational convention: $X \mid$ success implies the "outcome $X$ given successful execution."
} 
to a successful one. There is ample evidence that different organizations treat managers in various ways following the outcome of an initiative. To some extent, such unwritten rules characterize "the way things are done" in a particular firm and reflect the organizational culture (Schein 2010, Hermalin 2013). We focus on a particular dimension of the organizational culture that has recently drawn more attention: the tolerance for failure (Manso 2011, Hutchison-Krupat and Chao 2014), as expressed by the magnitude of the penalty the organization imposes on a manager following a failed NPD initiative. In reality, failure may manifest itself through an abrupt stop in a subsequent gate review, or portfolio meeting.

Based on first-hand discussions with senior NPD managers, we assume the penalty bestowed upon the managers is proportionate to the total resources committed to the initiative. As an example, functional managers may incur significant indirect costs upon failure, e.g. a diminished intra-organizational status, reflected in the career paths or development programs the manager is considered for. We incorporate the penalty through a parameter, $k_{2}>0$, that expresses the penalty per unit of resource "wasted" on a failed initiative. With this interpretation, we depart from the common assumption of limited liability in principal-agent models. Since these penalties may not necessarily reflect explicit policies of a firm, we assume that they are harder to change, at least within the context of a single initiative.

In summary, when the initiative is successful the functional managers receive utility $U_{i}(\cdot) \mid$ success $=$ $k_{1} \Pi_{s}$ and when the initiative fails the functional managers receive utility $U_{i}(\cdot) \mid$ failure $=k_{2} \Pi_{f}$ for $i \in\{a, b\}$. Our modeling assumptions serve two explicit goals:

- The utility functions are risk neutral. Our assumption aims to avoid any a-priori risk bias. We do so in order to isolate the organizational effects, as opposed to individual behavioral traits, a usual excuse provided to justify an organization's lack of investment in risky initiatives (see Bhattacharya and Mookherjee 1986, Hauser 1998, Brady 2005, Economist 2006, Hamm 2009).

- There is no explicit private cost for each of the functional managers. The only private component is the functional capability, $\eta_{i}$. In that regard, we avoid any explicit misalignment of objectives between the agents (managers) and the principal (VP), another highly cited reason for an organization's failure to pursue risky initiatives (Siemsen 2008, Mihm 2010, 
Definition of NPD Initiative

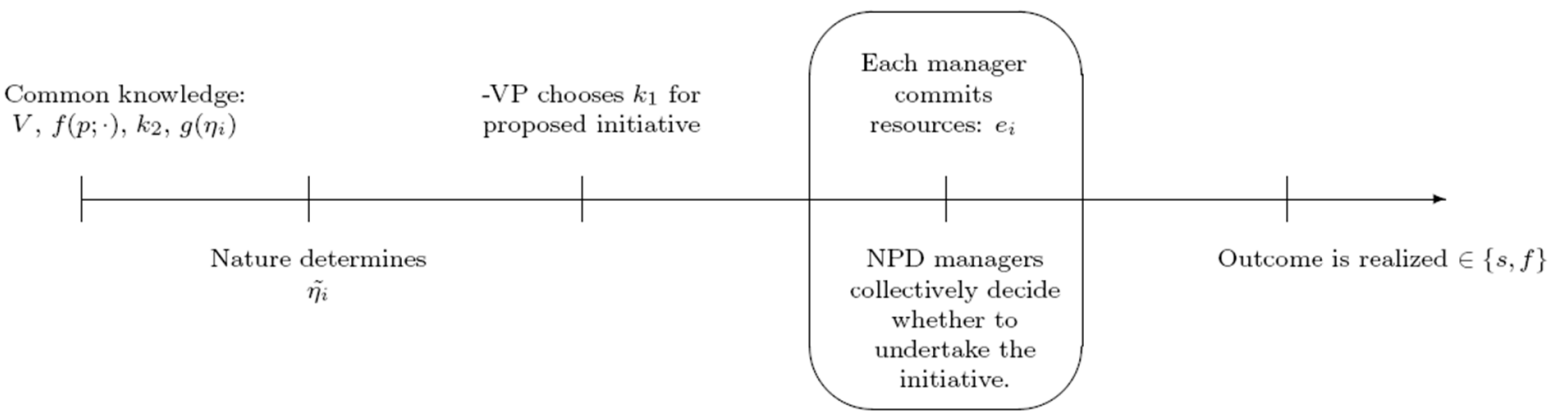

Figure 1: The sequence of events.

Manso 2011). In our model, the alignment between senior leadership's objectives and those of the managers is within senior leadership's discretion ${ }^{6}$. It is straightforward to check that the functional managers and the principal are aligned when $k_{1}=k_{2} /\left(1+2 k_{2}\right)$.

\subsection{Defining NPD initiatives: In or out of the portfolio?}

Within the previous context, we present the sequence of decisions that pertain to the definition and pursuit of an initiative in Figure 1. Senior leadership outlines the strategic direction of the firm and proposes a specific strategic initiative. The firm's organizational structure dictates whether the VP retains decision rights over each function's resource commitments. Regardless of decision rights, when there exists asymmetric information, the VP is unable to precisely determine, ex-post, whether the resources committed by either manager are appropriate given their exact capability. This early in the NPD process (i.e. the "fuzzy front-end"), there is not a 1-1 mapping between the managers' inputs, $\left(\eta_{i}\right.$ and $\left.e_{i}\right)$ and the probability of success, $p$.

Senior leadership presents each of the functional managers with a common performance plan that outlines: (i) whether or not the functional managers are empowered to choose the level of resources that are committed to the initiative; and (ii) the share of profits, $k_{1}$, the functional managers would receive contingent upon the successful execution of the proposed NPD initiative. Because the VP cannot decipher the exact contributions of either functional manager, she offers the

\footnotetext{
${ }^{6}$ Clearly, the degree to which a principal and an agent's objectives are aligned is always within the principal's discretion. What is important here is that when there is a private cost of effort, as is typical, a linear contract does not allow the principal to achieve full alignment; impose financial incentives such that the agent and the principal's preferred effort is the same given the same information.
} 
functional managers a common contract, where they each receive the same benefit proportional to the initiative's profit. Such incentives are not an artifact of our model; they have been advocated in the literature (Che and Yoo 2001, Loch and Tapper 2002).

If the functional managers are empowered to choose their resource commitments, we model the resulting consensus (or lack thereof) through the existence of a Nash equilibrium in a simultaneous move game. The simultaneous decision captures the salient features of the interactions: (i) it offers a realistic proxy for the often advocated need to mutually agree upon an objective (e.g. no party has an incentive to deviate; all stakeholders need to "buy into" the initiative); and (ii) it retains the underlying interactions (e.g. each party accounts for the potential of no commitment from the other side). Thus, if the functional managers reach an agreement and it satisfies the VP (who maintains the authority to veto an initiative), then they pursue the initiative according to the mutually agreed upon commitments. If no consensus is reached (no equilibrium exists), then we assume the initiative is not pursued. Upon completion of the initiative, the outcome is either a success or a failure, and rewards and recognition (or penalties) are distributed.

\section{Model Analysis}

We proceed with our model analysis as follows: First, we examine the optimal decisions of each of the stakeholders in a setting of full information regarding the functional managers' capabilities; without any information asymmetry. Full information does not imply the the initiative lacks uncertainty. Indeed, there still remains uncertainty regarding the probability of success, and the eventual outcome.

Under full information, we analyze three scenarios. (i) The first-best scenario, where a centralized decision-maker (i.e., the proverbial master-mind) makes and executes all decisions, i.e., no functional managers are required, an (unrealistic) scenario in which the VP chooses the resource commitments and manages the detailed tasks of both functions; (ii) Task specialization without empowerment, where the VP decides on the resource level to commit but relies on the functional managers to execute on her resource decision, such that the VP only chooses incentive compensation to satisfy the functional managers' reservation utility; and (iii) Task specialization with empowerment, where the VP delegates the resource commitment decision to the functional managers, so 
that the VP must choose incentive compensation that induces the functional managers to commit resource commitments.

Our analysis of the full information setting allows us to build intuition and to establish a benchmark for our subsequent analysis of asymmetric information. Throughout our analysis, we use the superscript $j \in\{f, a\}$ to denote the information structure, full information or asymmetric information, respectively. Likewise, we use the superscript $k \in\{f b, c, d\}$ to denote the locus of decision rights, either first-best (no functional managers), centralized (the VP decides resource commitments), or decentralized (functional managers decide resource commitments). Such that $e_{a}^{f, d}$ would represent the resource commitment for function $a$ in a setting where there is full information and the decisions on resource commitments are decentralized (the functional managers are empowered).

\subsection{Full information: first-best}

In the first-best case neither the penalty for failure nor the incentives play a role in the VP's decision-making process. Indeed,the VP bears the full burden of any gain or loss resulting from the initiative. However, for all other cases (when the functional managers are required) the VP must share her reward and consider the penalty imposed on the functional managers when she designs incentives. Of course, even when the functional managers carry out the management and detailed allocation of resources, the VP still carries the full burden of the resources committed to the initiative.

Senior leadership's objective is to maximize her utility (firm profit) through her decision on $e_{a}, e_{b}$. The following proposition describes the VP's optimal decisions.

Proposition 1. First-Best Resource commitment

- The optimal centralized resource commitment, $e_{a}^{f b}=e_{b}^{f b}=e^{f b}$ implicitly solves:

$G^{f b}(e)=e^{4} N^{2}+2 e^{2} N-e N V+1=0$, where $N=\eta_{a} \eta_{b}$.

- The set of feasible initiatives is $\mathcal{P}^{f b}=\left\{V, N \in \mathbb{R}_{+}: V \sqrt{N} \geq 4\right\}$

Proof. All proofs are provided in the Appendix to enhance readability.

Proposition 1 provides the optimal resource commitments for the firm in a first-best setting. The resource commitment is symmetric for both functions and proportional to the overall capability 
of the organization (as captured by $N=\eta_{a} \eta_{b}$ ). As the overall capability of the organization increases, the resource commitment decreases, that is capability acts as a substitute for resources. Furthermore, to address the question of how the characteristics of an organization affect its potential to pursue various innovation objectives, we provide the first-best benchmark of feasible initiatives, $\mathcal{P}^{f b}$; the set of initiatives the firm can pursue and still expect a non-negative profit, given their capabilities.

The feasible set of initiatives under the first-best echoes the same sentiment that Markowitz (1952) captures with his notion of an attainable set of financial investments (Markowitz, 1952, p. 85). Moreover, this feasible set serves as the benchmark upon which we provide a different theoretical view of the portfolio of initiatives. That is, the first-best can be viewed as the set of initiatives that could potentially be available under ideal (arguably unattainable) conditions. Then, our subsequent analysis of the different organizational factors helps to delineate the feasible set of initiatives that is attainable by a specific organization. Therefore, cross organizational comparisons of portfolios without consideration for the organization itself are incomplete.

\subsection{Full information: centralized decision rights and task specialization}

A more realistic context than the first-best setting is one where there exists task specialization such that the functional managers carry out the detailed management of the resources assigned to an initiative. That is, the VP may still decide on the resource commitments for each function, but the VP relies on the functional managers to ensure the resources are properly utilized. The critical difference between the this setting and the first-best is that the VP must ensure that the she provides adequate incentives for the functional managers to pursue the initiative. In other words, the VP must provide incentives such that managers' expected utility at least meets their reservation utility ${ }^{7}$. We replicate the standard result of many full information, principal-agent models in Economics (Akerlof 1970, Fudenberg and Tirole 1992): senior leadership pays both managers a fixed wage equivalent to their expected penalty as a result of a failure. Since the managers are risk neutral, they are indifferent between a fixed wage or an appropriately set, output contingent, linear incentive $\left(k_{1}\right)$. As such, for expositional clarity and consistency, we report our

\footnotetext{
${ }^{7}$ Following prior literature, we normalize the reservation utility to zero. Reservation utilities different from zero do not change the qualitative nature of the results.
} 
results in terms of the linear incentive scheme, $k_{1}$.

Senior leadership's optimal decisions reveal the realities of task specialization. Because the VP is required to cover the participation constraint of the functional managers, the set of initiatives she can feasibly pursue is reduced.

\section{Proposition 2. TASK SPeCialization With CENTRALized DECiSION Rights}

i) The optimal resource commitment, $e_{a}^{f, c}=e_{a}^{f, c}=e^{f, c}$ solves:

$$
\begin{aligned}
& G^{f, c}(e)=e^{4} N^{2}+k_{2}\left(2-2 e^{2} N\right)+2 e^{2} N-e N V+1=0, \text { the optimal incentive is } k_{1}^{f, c}= \\
& \frac{2 k_{2}}{e^{f, c} N V-2\left(e^{f, c}\right)^{2} N}, \text { and } e^{f, c} \geq e^{f b} .
\end{aligned}
$$

ii) The feasible set of initiatives is smaller than the first-best setting, $\mathcal{P}^{f, c} \subseteq \mathcal{P}^{f b}$.

iii) The feasible set of initiatives $\mathcal{P}^{f, c}$ becomes smaller as the penalty for failure, $k_{2}$, increases.

Senior leadership must provide compensation to the functional managers to offset any exposure they have to penalties they could experience if a failed initiative is realized. Naturally, managers who are exposed to a larger penalty for failure require greater upside compensation to offset this potential penalty. This means the VP is left with a smaller portion of profits when she pursues a new initiative in a high penalty environment. This also means that an initiative that would be profitable in a low penalty environment, might not be profitable in a high penalty one. Subsequently, the feasible set of initiatives becomes smaller as the penalty for failure increases.

A full information setting in which there is specialization (functional managers) and the VP decides on resource commitments results in an over-investment, as compared to a first-best setting. Specialization requires the VP to sacrifice a portion of her surplus to ensure the functional managers' participation constraint is met. To compensate for this, the VP over-invests, which results in a higher probability of a successful outcome, albeit with higher cost. This result is managerially relevant as it sheds light on an inherent trade-off that senior leadership faces. The probability of success is increasing in the resource commitment; yet, an increase in the resource commitment has a two-pronged impact: it directly increases cost, which also increases indirect costs. Specifically, an increase in the cost means the functional managers are exposed to a larger penalty, which requires the VP to increase the compensation to the functional managers, which is also more costly. 


\subsection{Full information: delegated decision rights and task specialization}

We now shift our analysis to a VP who delegates the resource commitment decision to the managers. We analyze this setting to tease out the impact of information asymmetry in our subsequent analysis. Indeed, when there is full information, and given the option, the VP would never choose to delegate decision rights. Still, in a full information setting where decision rights are delegated, the VP must ensure the incentives she offers the functional managers, at least, meets their participation constraint. Moreover, she must set incentives to induce the functional managers to select a profit maximizing resource level. Theorem 1 outlines the decisions for such a setting.

\section{Theorem 1. The EFFECT OF SPECIALIZATION AND DELEGATION}

i) The optimal resource commitment of each functional manager $e_{a}^{f, d}=e_{b}^{f, d}=e^{f, d}$ is always larger than the VP's resource commitment when she maintains decision rights; $e^{f, d}>e^{f, c}>$ $e^{f b}$.

ii) The VP's decision on incentives is such that $k_{1}^{f, d} \leq k_{2} /\left(1+2 k_{2}\right)$.

iii) The set of feasible initiatives is independent of decision rights, $\mathcal{P}^{f, d}=\mathcal{P}^{f, c} \subset \mathcal{P}^{f b}$.

\section{Corollary 1. DeCEntralized PROFItS}

i) It is always more profitable for the firm to centralize the decision rights regarding resource commitments.

ii) For initiatives strictly inside the feasible set, the incentive contract offered under centralized decision rights will be greater than that offered under decentralized decision rights.

The VP always carries the full burden of both functions' resource commitments, while she only retains a portion of the profits if successful. Indeed, the VP's objectives are driven by the ratio between the profit she can retain following a success and the burden she must carry following a failure. In contrast, the functional managers are exposed to some portion the initiative's costs if a failure is realized and some fraction of the profits, if the initiative is successful. As such, when the functional managers are endowed with decision rights, their objective can also be defined by the ratio between the incentive compensation they receive following a success as compared to the penalty they incur if it fails. 
Specifically, the VP's decisions are driven by the ratio between the impact they incur following a failure as compared to the benefit they yield following a success, $\frac{\left(1-2 k_{1}\right) \Pi_{s}}{\Pi_{f}}$. And, if the functional managers are endowed decision rights, then their decisions are driven by the ratio: $\frac{k_{1} \Pi_{s}}{k_{2} \Pi_{f}}$. If the VP were to align the objectives of the functional managers with those of her own-establish the same relative exposure to upside and downside risk as herself-she could do so be setting $k_{1}=\frac{k 2}{1+2 k_{2}}$. However, under full information, the VP chooses to maximize profits by establishing $k_{1}^{f, d}<k_{2} /(1+$ $2 k_{2}$ ) for all initiatives in the interior of the feasible set and only for those on the boundary, i.e.,

where expected profit is zero, does she set $k_{1}^{f, d}=k_{2} /\left(1+2 k_{2}\right)$. That is, the VP chooses to force the functional managers to absorb a greater relative portion of the downside than she imposes on herself.

Corollary 1 highlights the distinction between centralization and decentralization of decision rights. First, it should come as no surprise that when endowed with full information, the VP would never be better off delegating the decision on resource commitments; doing so only reduces her profits. Regarding the incentives, Theorem 1 shows that the incentives offered to the managers are equivalent at the boundary of the feasible set. However, as we move to the interior of the feasible set, the incentives required under centralized decision rights are strictly greater than those required when decision rights are decentralized.

We now turn to the more realistic context of the NPD front-end where senior leadership lacks full information on the functional managers' capabilities.

\subsection{Asymmetric information: delegated decision rights}

We assume that if functional managers, who have decision rights over their own resource commitments, cannot reach a consensus then they do not pursue the initiative. Recall, the functional managers' capability is symmetrically distributed such that each function has an equal probability of having either a high or low capability (i.e. $\tilde{\eta}_{i} \in\{\ell, h\}$ and $P\left(\tilde{\eta}_{i}=\ell\right)=P\left(\tilde{\eta}_{i}=h\right)=1 / 2$ ). As our interest is on the impact of information asymmetry, we operationalize the functional managers capabilities such that $\tilde{\eta}_{i} \in\{\ell, h\}$ corresponds to $\tilde{\eta}_{i} \in\{\mu(1-\delta), \mu(1+\delta)\}$, so that $\delta$ is linearly proportional to the coefficient of variation.

There exist four possible realizations of the functional managers' combined capability (three, given the symmetry, since $N=\eta_{a} \eta_{b}=\ell h$ is equivalent to $N=h \ell$ ) such that if the VP wants 
to ensure a functional manager with a low realized capability pursues the initiative, she must offer a higher incentive $\left(k_{1}\right)$. Thus, despite the VP's desire to tailor the resource commitments to the functional managers' specific capability, she is limited in her ability to do so. Specifically, she must choose incentives to induce the functional managers to only pursue the initiative if their combined capability is sufficiently high. That is, she chooses an incentive for the minimum combined capability she is willing to accept. We use an additional superscript $m$ to denote the specific

performance plans, so that $k_{1}^{a, d, \ell \ell}$ indicates that the VP seeks to induce the functional managers to pursue the initiative independent of their capability; we suppress the $a, d$ notation where possible for expositional clarity. In line with prior results, trivially, $k_{1}^{h h}<k_{1}^{\ell h}<k_{1}^{\ell \ell}$. Therefore, if decision rights were delegated and the VP were to offer $k_{1}<k_{1}^{\text {all }}$, and both functions realized a low capability, then they would not choose to pursue the initiative. The theorem below outlines the key results for an asymmetric setting.

\section{Theorem 2. Delegation In the PRESEnCE OF INFORMATION ASYMMETRY}

Let $N_{\text {min }}$ be the minimum combined capability for which the VP seeks to pursue the initiative.

i) If the functional managers realize a combined capability of

$$
\tilde{N}= \begin{cases}N_{\text {min }} & \text { then } e^{a, d}=\frac{v}{4} \\ N>N_{\text {min }} & \text { then } e^{f b}(N)<e^{a, d}(N)<\frac{v}{4}\end{cases}
$$

ii) If $N_{\min }=h h$ then $e^{a, d, h h}=e^{f, d}(N=h h)$.

iii) For $N_{\text {min }}<$ hh the set of feasible initiatives $\mathcal{P}^{a, d}\left(N_{\min }\right) \subset \mathcal{P}^{a, d, N_{\text {min }}}$.

iv) For $N_{\text {min }}<$ hh there exists a threshold $\hat{V}\left(\delta, k_{2}\right)$ such that if $V<\hat{V}\left(\delta, k_{2}\right)$ then the VP chooses $k 1>\frac{k_{2}}{1+2 k_{2}}$, otherwise $k 1 \leq \frac{k_{2}}{1+2 k_{2}}$.

Delegation offers the VP the ability to allocate decision rights to those who hold the best knowledge of the organization's capability to execute the initiative. If the VP delegates the resource commitment decision and the minimum capabilities are realized, then she faces a similar situation to the findings of Theorem 1: over-investment. There is a bright side, though. If the functions' realized capability is greater than the VP's minimum acceptable level, $N_{\min }$, then the managers' over-investment in resources is reduced such that the resource commitment is closer to the first-best 
Low $k_{2}$

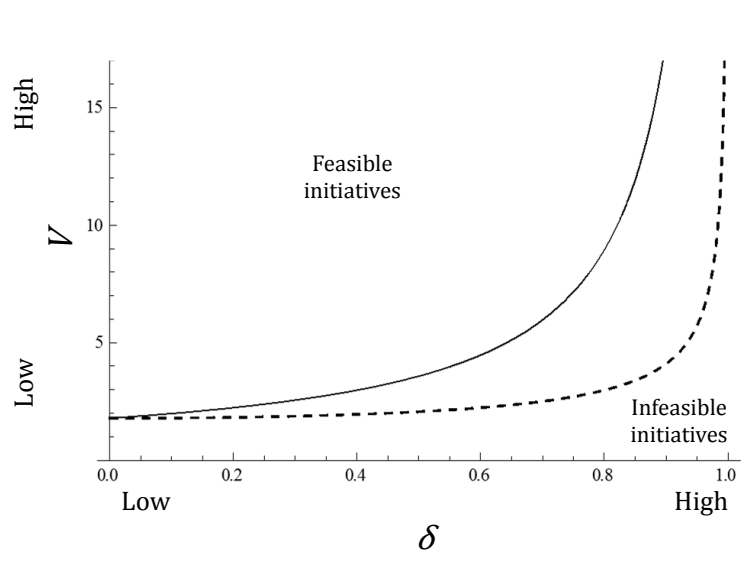

Boundary of feasible set of initiatives under $N_{\min }=\ell$

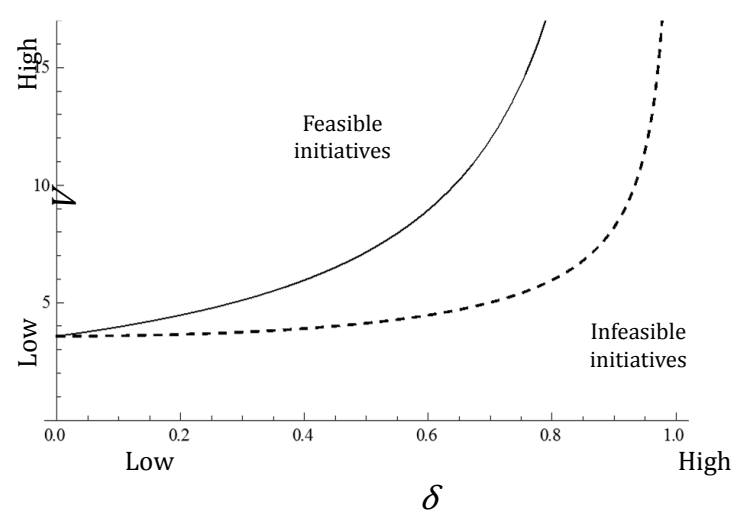

$\delta$

Figure 2: Feasible sets under delegated decision rights given the VP's decision on $N_{\min }$ and differing penalties for failure.

level. Moreover, the higher the realized capability is, the closer the resource commitment is to the first-best level. However, this does, of course, comes at the cost of the increased incentives.

Alternatively, the VP could increase her minimum acceptable capability. This has the benefit of increasing the feasible set and decreasing the incentive she must offer. However, this too comes at a significant cost. After all, an increase in the minimum capability means that the initiative may not be pursued. When the VP delegates decision rights and offers a contract that induces functional managers to pursue the initiative regardless of their true capability $\left(k_{1}^{a, d, a l l}\right)$, she limits the set of feasible initiatives to only those initiatives that are "doable" for the entire organization, i.e., initiatives where it is well-understood that the functional capabilities exist (e.g. incremental initiatives). This poses a significant challenge for the organization: to pursue the largest set of initiatives requires an incentive plan of $k_{1}^{a, d, h h}$. And while this allows the VP the same benefits she has under full information, this translates to only a $25 \%$ chance that an initiative ultimately "gets off the ground." Indeed, the likelihood that both function's capabilities for any given initiative are high is $P\left(\eta_{a}=h\right) P\left(\eta_{b}=h\right)=1 / 4$. These results are graphically depicted in Figure 2 .

When decision rights are delegated and the VP seeks to pursue an initiative near the boundary of the feasible set the VP always chooses incentives to align the organization in such a way that the firm 


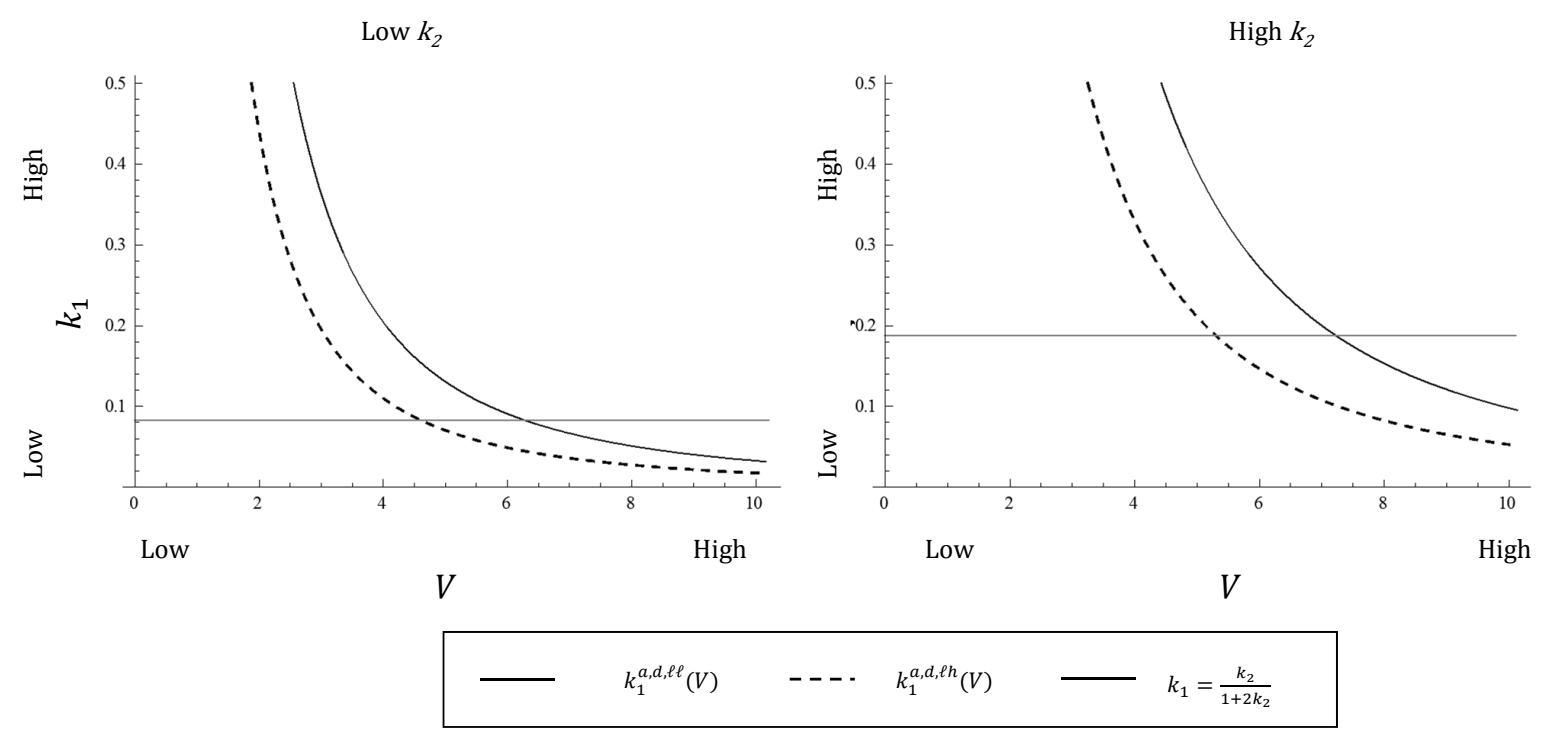

Figure 3: The VP's incentive decision and organizational alignment as it relates to the initiative's value for varying degrees of penalty for failure.

absorbs failure to a greater extent than the functional managers; the VP "protects" the managers. The degree to which the VP seeks to protect the managers from potential penalties depends on just how much the VP seeks to push the boundary (how close to the boundary she chooses to go), the penalty for failure, and the minimum capability she is willing to accept. Specifically, as graphically depicted in Figure 3, if the VP seeks to induce alignment similar to the full information case, she must choose initiatives that are substantially inside the feasible set (i.e. at least $40 \%$ greater than the minimum valued initiative the VP could pursue). Indeed, regardless of the magnitude of the penalty for failure, and independent of whether $N_{\min }=\ell \ell$ or $N_{\min }=\ell h$, the VP always needs to offset the penalty with higher incentives if she wants the organization to adopt initiatives near the boundary.

However, as with the feasible set, how she perceives an individual initiative also depends on what she chooses as her minimum acceptable capability. It follows that there are initiatives for which the VP would have to offer substantially high incentives (i.e., to protect the managers) under an $N_{\min }=\ell \ell$ contract but far lower incentives (those that shift burden to the managers) if instead $N_{\text {min }}=\ell h$. The same trade-off persists: the VP could choose this strategy, but doing so means the initiative has a higher risk of never being launched. 


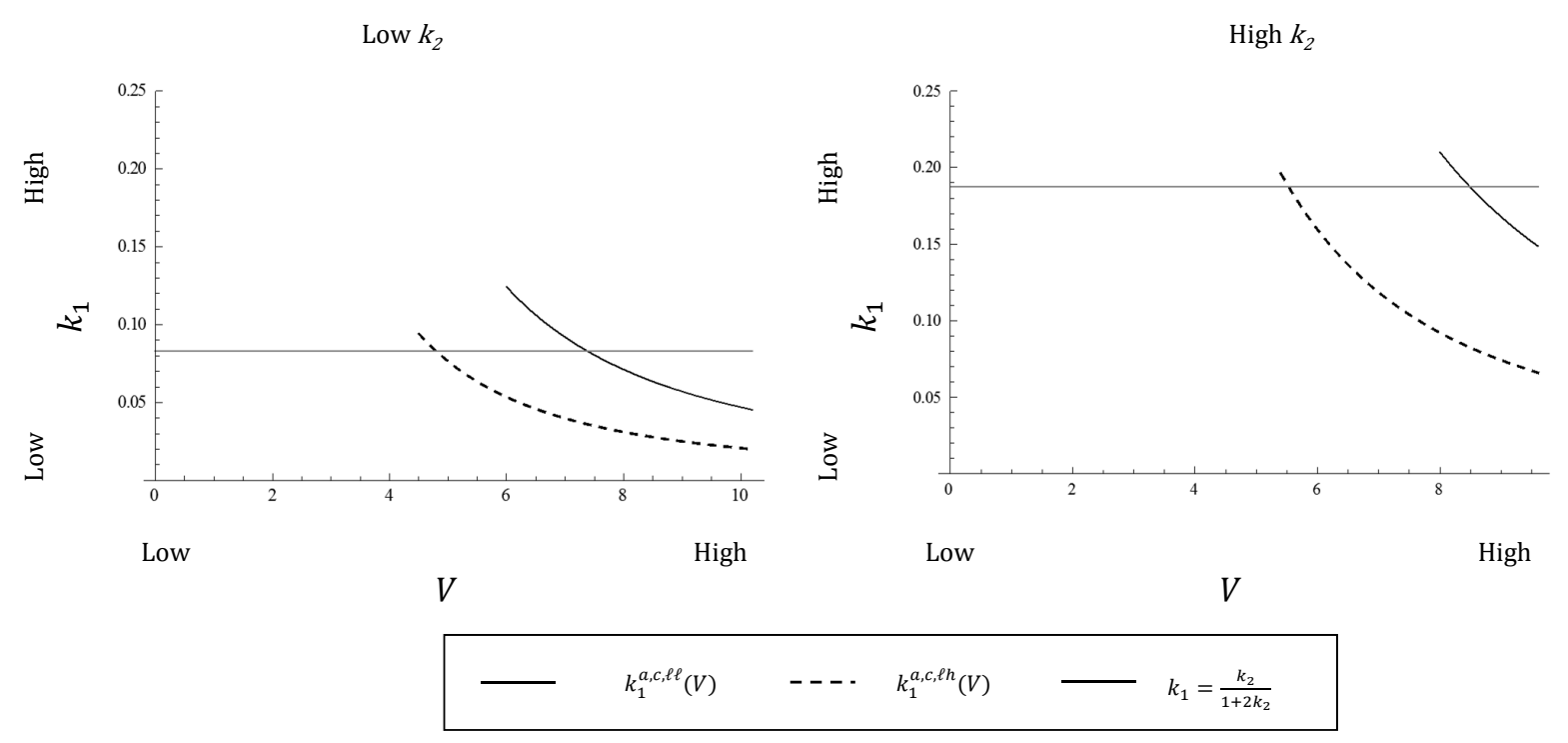

Figure 4: Incentives under centralized decision rights given the VP's decision on $N_{\min }$ and differing penalties for failure.

\subsubsection{Centralized decision rights in the face of asymmetry}

As in the prior section, the VP does not know the each functions' exact capability, while the functional managers clearly do understand their own capability as well as their combined capability. Similar to Theorem 2, the VP chooses incentives designed for the minimum functional capability she is willing to accept. Thus, as with delegated asymmetric information, if she only seeks to pursue the initiative when both functions are of a high capability, the analysis reverts to full information.

Theorem 3. Centralized DeCision Rights in the PRESEnCE of INFORMATion ASymmetry

i) For all $N_{\text {min }}<$ hh the set of feasible initiatives $\mathcal{P}^{a, c, N_{\min }} \subset \mathcal{P}^{a, d, N_{\text {min }}}$.

ii) For all $N_{\min }<h h$, and sufficiently low $V$ or high $\delta$, the VP optimally chooses $k_{1}^{a, c}>\frac{k_{2}}{\left(1+2 k_{2}\right)}$.

In stark contrast to the full information setting, the feasible set of initiatives under centralized decision rights is smaller than it is under delegated decision rights. The rationale comes from Theorem 2, where we find that the resource commitments are not only tailored to the individual functions' capabilities, but they are tailored in a way that brings them closer to the first-best, thus reducing inefficiency. In contrast, a VP who maintains decision rights must try to find a resource commitment that balances all possible capabilities. Of course, the exception is if the VP chooses 
$N_{\min }=h h$. Such a strategy de-facto establishes full information at the cost of a lower likelihood the initiative is eventually pursued.

In a similar manner to the case of delegated decision rights under asymmetric information in concert with centralized decision rights implies the VP may need to offer an incentive that aligns the organization in such a way that the functional managers' impending penalties are offset by higher incentives. However, just as the VP must offer lower incentives, on an absolute basis, when decision rights are centralized, so too is the case with the degree to which she must offset the managers penalties. In other words, centralized decision rights do not require the VP to offset penalties to the same degree as she must do under delegation (see Figure 4 for a graphical depiction).

Despite the limitations placed on the feasible set and the higher incentives, there is a bright side to centralized decision rights. Specifically, for projects inside the feasible set the VP can expect higher profits when she maintains decision rights. Indeed, profitability can be exploited but doing so limits the initiatives the organization views as feasible options. Figure 5 graphically depicts the difference between profits when decision rights are centralized and when they are delegated for varying degrees of information asymmetry. The vertical lines represent the boundary of the feasible set under the different decision rights, where the centralized boundary is clearly inside the boundary under delegation. Then, the curves represent the difference in profit for a given value for each level of asymmetry. All curves start out where delegated is slightly more profitable, however, when information asymmetry is low there are only a small portion of the initiatives are more profitable under delegation. In contrast, when information asymmetry is more substantial, delegation offers benefits even far inside the feasible set. Thus, the argument that centralized decision rights yield more profits, may be true, yet this is only the case if the set of initiatives the firm considers is restrictive as compared to what is possible.

\section{Front-end portfolio decisions: An alternative perspective}

In this section, we further discuss the core implications of our model analysis. We link our findings to the following core managerial challenges: i) How are new NPD initiatives defined and what are the resulting implications for the firm portfolio?; and ii) How does an organization's tolerance for failure affect how senior leadership aligns its own objectives with those of mid-level management? 


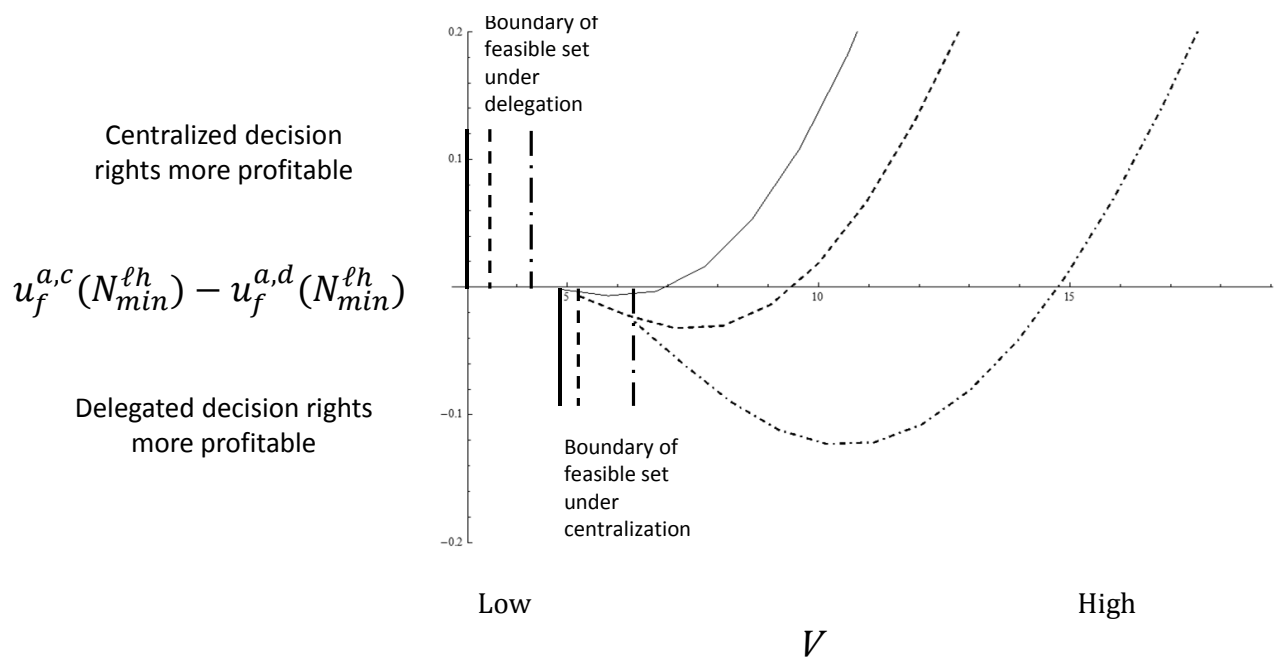

$\delta=0.35$ under $N_{\min }=\ell h$

$\delta=0.55$ underunder $N_{\min }=\ell h$

$\delta=0.75$ underunder $N_{\min }=\ell h$

Figure 5: Difference between the expected utility the VP (firm) can expect under either centralized or delegated decision rights for differing levels of information asymmetry, when $N_{\min }=\ell h$ and $k_{2}=\frac{1}{4}$.

\subsection{Defining NPD initiatives: challenges and insights}

The nexus of this research lies in the challenges senior management faces when they must alter the composition of their firm's portfolio to promote an innovative NPD initiative and implement a strategic objective. Traditionally, the portfolio selection problem has been approached as a managerial decision, where the manager "selects from a menu". As such, academics generally resort to a series of mixed-integer programming formulations, i.e., "knapsack problems" (e.g. Fox et al. 1984), where the challenge is to choose the most valuable set of initiatives within the firm's budget capacity (Kavadias and Chao 2007). Such a perspective neglects an important dimension: portfolio decisions are top-down strategic directives that get implemented at different organizational levels (Anderson and Joglekar 2005, Bower and Gilbert 2005, Chao and Kavadias 2008, Hutchison-Krupat and Kavadias 2014, Hutchison-Krupat 2017). These decisions are made even more challenging because the knowledge required to implement these innovative initiatives is dispersed across multiple functions (Sosa et al. 2002, Blindenbach-Driessen 2015, Schlapp et al. 2015, Hutchison-Krupat and Kavadias 2017). As such, organizations find it difficult to define, support and implement strategic initiatives (Bower 1970, Loch and Kavadias 2011, Kim et al. 2014). In other words, even if an 
initiative is feasible for some organization, it does not mean it is feasible for any organization.

Our view posits that there is a critical step that has received less attention, and as such, is undervalued: an organization's structure (decision rights and incentives), which enables (or negates) the pursuit of specific strategic initiatives. Figure 2 (i) shows the effect that information asymmetry has on the firm's ability to implement strategic initiatives. Senior leadership, who faces asymmetric information and offers incentives, experiences a significant reduction in the firm's set of feasible initiatives as this information asymmetry increases. Thus, despite the existence of an innovative initiative, a specific organization may not view it as feasible, solely as a result of the information asymmetry and the organizational dynamics between stakeholders.

So, if additional initiatives do potentially exist and match the firm's strategy, what can senior management do to enable their organization to pursue them? The firm has three potential levers: the first two are short-term levers and include the ability to adjust the incentives and the allocation of decision rights; the last is a long-term lever that requires senior leadership to influence the penalty for failure and take control over a greater scope of decisions. What is interesting is that the former strategies reflect the opening example of GSK, and the latter reflects the strategy of Wyeth.

An organization can expand its feasible set by ensuring that the initiative is only pursued if the functional managers are, in fact, of a high capability. Yet, there is a significant trade-off: such an incentive scheme is only possible a fraction of the time (i.e. on expectation $25 \%$ ). This is simply because there are a limited number of high-performance teams within the organization. Thus, while it may be possible to push the organization in the short-term to pursue additional risky initiatives through the provision of incentives, the limited utilization of resources may be an unsustainable situation for the firm.

Empowering the NPD organization is beneficial, especially if the information asymmetry is large. But large information asymmetries already imply a drastically reduced feasible set, and this is surely not desirable trait, in and of itself. This findings complements the insights we gleaned from incentives; neither of these short term remedies is a complete solution to the firm's ability to profitably pursue the largest set of initiatives.

Ultimately, longer term actions to lower the penalty for failure prove to be the path to achieving sustainable results. The increase in the feasible set of initiatives that occurs as a result of such a shift does not face the utilization challenges, as previously discussed. In other words, here the feasible set 
holds true for managers regardless of the capability of the function they oversee. However, again we face a significant trade-off: substantial research shows that achieving such a "organizational transformation" is an extremely difficult (some claim impossible) and costly process (Poole and Van de Ven 2004). However, a reduction in the penalty for failure prompts senior leadership to alter the organization's alignment in non-obvious ways, as we discuss below.

Of course, what we have not captured, and what remains an interesting topic for future research, is the dynamic relationship between information asymmetry and decision rights. That is, when senior leadership takes away decision rights from functional managers, does this increase the potential for greater information asymmetry?

\subsection{The relationship between tolerance for failure and organizational alignment}

Our analysis of both delegated and centralized decision rights under information asymmetry reveals key drivers of organizational alignment. Specifically, as Proposition 2 and Theorem 1 reveal, absent any information asymmetry the VP always (mis)aligns the organization in such a way that the functional managers incur a greater relative burden for a failed initiative than the firm. Importantly, this is independent of the penalty for failure the firm imposes. However, our analysis of the settings in which there is information asymmetry reveals that the the VP may impose incentives that (mis)align the organization in a such a way that the functional managers incur less of a burden than the firm itself; the VP seeks to offset the potential penalties imposed on the functional managers through the provision of incentives.

In particular, Theorem 2 and 3 provides insights on what drives the provision of incentives in such a way that the organizational alignment shifts in such a way that the VP essentially protects the functional managers from impending penalties through the provision of incentives. When decision rights are delegated, far greater incentives are required to get the minimum capability manager to pursue initiatives at the boundary of the (asymmetric) feasible set. Under both delegated and centralized decision rights, increased information asymmetry increases the disparity between the incentives the VP must offer when she chooses between different minimum capabilities. In other words, when there is greater information asymmetry there is a greater chance that the VP would not need to offer high incentives to protect the functional managers if she employs an $N_{\min }=\ell h$ incentive whereas she would need to offer such incentives if she employed an $N_{\min }=\ell \ell$ incentive. 


\section{Conclusion}

In this paper we develop a model to explore the impact that a firm's structural decisions, incentives and decision rights, have on the initiatives that ultimately make it into the firm's NPD portfolio. In that respect, we focus on the interactions between senior management (VP), who decides on the incentives, and two functional managers, who oversee the contributions of their respective groups during the collaborative implementation of the initiative. Two important dimensions determine whether different initiatives are pursued: the asymmetry of information between senior leadership and the functional managers who implement strategic initiatives, and the penalties imposed upon failure.

Our analysis departs from the traditional view of portfolio decisions (Kavadias and Chao, 2007), which focuses on an optimal allocation of resources given a menu of initiatives. In line with the field-research beginning with Bower (1970), and in a manner similar to Markowitz (1952), we view a firm's portfolio decisions as being contingent on some "environmental" parameters. In the case of Markowitz, these factors are an individual investor's risk attitudes, and for us these factors are the information asymmetry and the penalty for failure present in an organization. We view portfolio initiatives as the result of a compromise among stakeholders. Indeed, different stakeholders must support the implementation in a game theoretic sense, i.e. no party should have any incentive to default on the initiative's execution.

Our analysis provides complements existing literature that analyzes the portfolio decisions to pursue given a specific initiative (with positive expected value). Rather than solely assume that we have initiatives at our disposal that are interior to the feasible set, we evaluate how structural decisions affect the initiatives an organization would even choose include in their consideration set. This is, in fact, an important and fundamental consideration for senior leadership. Naturally, senior leadership does not seek to make decisions that knowingly limit their potential to innovate. In that light, our work aims to initiate a discussion on how a firm should align their NPD portfolio with its NPD organization. Or, said differently, what type of an organization a firm should strive for if it seeks a certain type of innovation portfolio. 


\section{Appendix}

For the proofs that follow, without loss of generality, we normalize the fixed wage portion, $w_{i}$ of the contract offered to the managers to zero.

Lemma 1. Stakeholders' expeCted Utility When DeCision Rights are Centralized.

VP(firm): Centralized (implementation and decision rights): $u_{f}^{f b}=\frac{\eta_{a} e_{a} \eta_{b} e_{b} V}{1+\eta_{a} e_{a} \eta_{b} e_{b}}-\left(e_{a}+e_{b}\right) ;$ Centralized decision rights (decentralized implementation): $u_{f}^{f, c}=k_{1} \frac{\eta_{a} e_{a} \eta_{b} e_{b}\left(V-e_{a}-e_{b}\right)}{1+\eta_{a} e_{a} \eta_{b} e_{b}}-\frac{\left(e_{a}+e_{b}\right)}{1+\eta_{a} e_{a} \eta_{b} e_{b}}$

Managers: Decentralized implementation: $u_{i}=k_{1} \frac{\eta_{a} e_{a} \eta_{b} e_{b}\left(V-e_{a}-e_{b}\right)}{1+\eta_{a} e_{a} \eta_{b} e_{b}}-k_{2} \frac{\left(e_{a}+e_{b}\right)}{1+\eta_{a} e_{a} \eta_{b} e_{b}}, \quad i \in\{a, b\}$

Proof. The centralized decision maker's utility follows directly from evaluating: $\mathbb{E}\left[p \mid e_{i}, \eta_{i}\right](V-$ $\left.\sum e_{i}\right)-\left(1-\mathbb{E}\left[p \mid e_{i}, \eta_{i}\right]\right)\left(\sum e_{i}\right), i \in\{a, b\}$. Similarly senior leadership with centralized decision rights follows directly from evaluating: $\left(1-2 k_{1}\right) \mathbb{E}\left[p \mid e_{i}, \eta_{i}\right]\left(V-\sum e_{i}\right)-\left(1-\mathbb{E}\left[p \mid e_{i}, \eta_{i}\right]\right)\left(\sum e_{i}\right)$, $i \in\{a, b\}$; and the utility of each of the managers when the task is decentralized follows from evaluating: $\left(k_{1}\right) \mathbb{E}\left[p \mid e_{i}, \eta_{i}\right]\left(V-\sum e_{i}\right)-k_{2}\left(1-\mathbb{E}\left[p \mid e_{i}, \eta_{i}\right]\right)\left(\sum e_{i}\right), i \in\{a, b\}$

Proof of Proposition 1. The first-best decision maker $k_{1}=k_{2}$ such that $u_{f}=\frac{\eta_{a} e_{a} \eta_{b} e_{b} V}{1+\eta_{a} e_{a} \eta_{b} e_{b}}-\left(e_{a}+e_{b}\right)$ For notational simplicity and without loss of generality we will use the notation $N$ to represent $\eta_{a} \eta_{b}$. When we evaluate the gradient and hessian of $u_{f}$ for the optimal solution, the symmetry between $e_{a}$ and $e_{b}$ is clear. In order to simplify the exposition of the centralized solution we evaluate the concavity of the following equivalent representation (by symmetry of $e_{a}$ and $e_{b}$ ): $u_{f}=\frac{N e^{2} V}{1+N e^{2}}-(2 e)$. When we do this, we find $u_{f}$ is concave for the domain $e \in\left[\frac{1}{\sqrt{3 N}}, \infty\right]$. Next we look at the domain for which $u_{f}$ is non-negative. We find this to be $e \in\left[\frac{V-\sqrt{V^{2}-16 / N}}{4}, \frac{V+\sqrt{V^{2}-16 / N}}{4}\right]$. Thus clearly $V^{2} N \geq 16$. As $u_{f}$ is increasing in $V$, this implies the necessary condition: $V \geq \frac{4}{\sqrt{N}}$. We first show that $e^{*}\left(V=\frac{4}{\sqrt{N}}\right) \geq \frac{1}{\sqrt{3 N}}$ lies in the concave and non-negative domains for $e$. We can easily solve for $e^{*}\left(V=\frac{4}{\sqrt{N}}\right)=\frac{1}{\sqrt{N}}$ which clearly satisfies the concavity conditions and is the minimal feasible $e^{*}$. Hence since $u_{f}$ is concave for all values greater than $\frac{1}{\sqrt{3 N}}$ and all $e^{*}$ lie strictly in this region any $e^{*}>\frac{1}{\sqrt{N}}$ is clearly a maximizer and must be non-negative. It follows that the feasible set of initiatives for the centralized decision maker is $\mathcal{P}^{f b}=\left\{N, V \in \mathbb{R}_{+}: N V^{2} \geq 16\right\}$.

Proof of Proposition 2. The solution for the principal with full information and centralized decision rights must satisfy the FOC such that $e_{i}=\frac{\sqrt{2 k_{1}\left(1-2 k_{1}\right)\left(N e_{j}^{2}-1\right)+\left(1-2 k_{1}\right)^{2} N e_{j} V}-\left(1-2 k_{1}\right)}{N e_{j}\left(1-2 k_{1}\right)}$, the condition 
on $k_{1}$, namely that $k_{1}^{f, c} \geq \frac{\left(e_{a}+e_{b}\right) k_{2}}{\eta_{a} \eta_{b} e_{a} e_{b}\left(V-e_{a}-e_{b}\right)}$ presents the participation constraint (PC) of the managers, obtained equating their expected utility to their reservation utility (normalized to 0 ). The participation constraint (PC) of the managers is always binding. As such we can represent $e_{i}^{f, c}$ as $e_{i}^{f, c}=\frac{-1+\sqrt{2 k_{2}\left(-1+N e_{j}^{2}\right)+N e_{j} V}}{N e_{j}}$. This also allows us to represent the principal's expected utility as $u_{f}^{f, c}=\frac{N e^{* 2}\left(v-2 e^{*}\right)-2 e^{*}\left(1-2 k_{2}\right)}{1+N e^{* 2}}$.

We define the feasible set of initiatives as follows:

Recall, $u_{f}^{f, c}=\frac{N e^{* 2}\left(v-2 e^{*}\right)-2 e^{*}\left(1-2 k_{2}\right)}{1+N e^{* 2}}$. We contrast this with the first-best utility $u_{f}^{f b}=\frac{N e^{f b^{2}}\left(v-2 e^{f b}\right)}{1+N e^{f b^{2}}}$ and by inspection it is clear that for any $k_{2}>0$ if $u_{f}^{c}=0 \Rightarrow u_{f}^{f, c}<0$. Thus we know that $\mathcal{P}^{f, c} \subset \mathcal{P}^{f b}$. In order to meet the principal's non-negativity constraint on $u_{f}^{f, c}$ we must have $e^{*} \geq \frac{V}{4}-\frac{\sqrt{N V^{2}-16\left(1+2 k_{2}\right)}}{\sqrt{N}}$ Which allows us to find the restriction necessary to define the feasible set of initiatives for the $f, c$ case; $V \geq \frac{4 \sqrt{1+2 k_{2}}}{\sqrt{N}}$. Thus we define $\mathcal{P}^{f, c}=\left\{N, V \in \mathbb{R}: V \geq \frac{4 \sqrt{1+2 k_{2}}}{\sqrt{N}}\right\}$. Define the boundary of the respective sets: $\mathcal{P}_{\text {min }}^{f b}=\left\{N, V \in \mathbb{R}: V^{2} N=16\right\}$ and $\mathcal{P}_{\text {min }}^{f, c}=\{N, V \in$ $\left.\mathbb{R}: V^{2} N=16\left(1+2 k_{2}\right)\right\}$, then clearly, as $k_{2}$ increases the set $\mathcal{P}^{f, c}$ gets smaller. Fixing $N$ and $V$ we have, $\mathcal{P}_{\text {min }}^{f, c} \mid k_{2}^{\prime}$ lies above $\mathcal{P}_{\text {min }}^{f, c} \mid k_{2}$ for $k_{2}^{\prime}>k_{2}$

\section{The EFFECT OF SPECIALIZATION AND DELEGATION}

i) The optimal resource commitment of each functional manager $e_{a}^{f, d}=e_{b}^{f, d}=e^{f, d}$ is always larger than the VP's resource commitment when she maintains decision rights; $e^{f, d}>e^{f, c}>$ $e^{f b}$.

ii) The VP's decision on incentives is such that $k_{1}^{f, d}<k_{2} /\left(1+2 k_{2}\right)$.

iii) The set of feasible initiatives is independent of decision rights, $\mathcal{P}^{f, d}=\mathcal{P}^{f, c} \subset \mathcal{P}^{f b}$.

Proof of Theorem 1. Recall that $u_{i}^{d c}=\frac{k_{1} \eta_{a} e_{a} \eta_{b} e_{b}\left(V-e_{a}-e_{b}\right)}{1+\eta_{a} e_{a} \eta_{b} e_{b}}-\frac{k_{2}\left(e_{a}+e_{b}\right)}{1+\eta_{a} e_{a} \eta_{b} e_{b}}$. The FOC imply $e_{i}^{d c}=$ $\frac{\sqrt{k_{1}\left(k_{2}-k_{1}\right)\left(N e_{j}^{2}-1\right)+k_{1}^{2} N e_{j} V}-k_{1}}{N e_{j} k_{1}}$. The same restrictions apply to the principal's utility in the $f, d$ case as in the $f, c$ case. Recall that in the $f, c$ case the principal was obligated to satisfy the PC of the managers. The feasible set for the $f, c$ case was driven by the non-negativity of the principal. We will show that $e_{i}^{f, d}$ is an upper bound for $e_{i}^{f, c}$. First we evaluate the best response of the managers when their PC is binding. The best response reduces to: $e_{i}^{B R}=\sqrt{e_{j} V}$, which greatly simplifies our evaluation. The equilibrium becomes $e_{i}^{f, d}=e_{j}^{f, d}=V / 4$. Thus for all parameters the managers face 
the same relationship between $V$ and $e$. As such in order to compare $e_{i}^{f, c}$ and $e_{i}^{d c}$ we can simply evaluate $e_{i}^{f, c}(V / 4)$.

$$
\frac{V}{4}-\frac{-4+\sqrt{4 N V^{2}+2 k_{2}\left(N V^{2}-16\right)}}{N V} \stackrel{?}{>} 0 \Rightarrow\left(N V^{2}-16\right)\left(N V^{2}-16-32 k_{2}\right)>0, \forall V>\frac{4}{\sqrt{N}} \text { and conclude }
$$

that $e_{i}^{d c}>e_{i}^{f, c}>e_{i}^{c}$. Furthermore as $k_{2} \rightarrow 0 \Rightarrow e_{i}^{f, c} \rightarrow e_{i}^{c}$ and as $V, N \rightarrow V, N: V=\frac{4 \sqrt{1+2 k_{2}}}{\sqrt{N}} \Rightarrow$ $e_{i}^{f, c} \rightarrow e_{i}^{d c}$

Although $e_{i}^{f, d}$ weakly dominates $e_{i}^{f, c}$ the feasible set of initiatives remains the same. We can easily verify this by looking at the principal's utility when $e=\frac{V}{4}$ and $k_{1}=\frac{16 k_{2}}{N V^{2}}$, when we do this we find $u_{f}\left(e^{d c}, k_{1}^{d c}\right)=\frac{V\left(N V^{2}-16-32 k_{2}\right)}{32+2 N V^{2}}$ it follows that $V>\frac{4 \sqrt{1+2 k_{2}}}{\sqrt{N}} \Rightarrow u_{f}>0$ and hence $\mathcal{P}^{f, d}=\mathcal{P}^{f, c}=\left\{N, V \in \mathbb{R}: V \geq \frac{4 \sqrt{1+2 k_{2}}}{\sqrt{N}}\right\}$

The necessary condition for $k_{1}$ when the managers $\mathrm{PC}$ is binding as: $k_{1}^{f, d}=\frac{16 k_{2}}{N V^{2}}$, which was obtained by substituting $e_{a}=e_{b}=V / 4$ into $k_{1}^{f, d}=\frac{\left(e_{a}+e_{b}\right) k_{2}}{\eta_{a} \eta_{b} e_{a} e_{b}\left(V-e_{a}-e_{b}\right)}$.

Clearly to have $k_{1}>k_{2}$ we would require that $\frac{k_{1}}{k_{2}}=1+\epsilon=\frac{16}{N V^{2}} \Rightarrow V=\frac{4}{(1+\epsilon) \sqrt{N}}$ but $\frac{4}{(1+\epsilon) \sqrt{N}}<\frac{4}{\sqrt{N}}$ and hence does not lie in $\mathcal{P}^{f, d}$ (nor $\mathcal{P}^{f b}$ or $\mathcal{P}^{f, c}$ for that matter) and thus we find a clear contradiction such that $k 1<k 2$.

\section{DECENTRALIZED PROFITS}

i) It is always more profitable for the firm to centralize the decision rights regarding resource commitments.

ii) For initiatives strictly inside the feasible set, the incentive contract offered under centralized decision rights will be greater than that offered under decentralized decision rights.

Proof of Corollary 1. i) Follows from the fact that senior leadership makes all decisions on $k_{1}$, e and can thus coordinate these optimally. ii)Recall the expected utility of the managers is $u_{i}=$ $k_{1} \frac{\eta_{a} e_{a} \eta_{b} e_{b}\left(v-e_{a}-e_{b}\right)}{1+\eta_{a} e_{a} \eta_{b} e_{b}}-k_{2} \frac{\left(e_{a}+e_{b}\right)}{1+\eta_{a} e_{a} \eta_{b} e_{b}}$ When their participation constraint is binding $\left(u_{i}=0\right): k_{1}=$ $\frac{\left(e_{a}+e_{b}\right) k_{2}}{\eta_{a} \eta_{b} e_{a} e_{b}\left(v-e_{a}-e_{b}\right)}$ We know from symmetry that $e_{a}=e_{b}=e$ and substituting $\eta_{a} \eta_{b}=N$ we have: $k_{1}(e)=\frac{2 e k_{2}}{N e^{2}(v-2 e)}=\frac{2 k_{2}}{N e(v-2 e)}$ and $\frac{\partial^{2} k_{1}}{\partial e^{2}}=\frac{4 \mathrm{k} 2\left(12 e^{2}-6 e v+v^{2}\right)}{e^{3} n^{2}(v-2 e)^{3}}$. We know that $v-2 e \geq 0$ (for there to exist any chance of positive utility). Thus let $h(e)=12 e^{2}-6 e v+v^{2}$ then if $h(e)>0$ then we know that $k_{1}$ for which the participation constraint is binding is strictly convex. Solving $h(e)=0$ yields $e=\frac{1}{12} v(3 \pm \sqrt{-3})$, clearly there is no real solution. Yet we can see that $h$ is a convex function in $e\left(\frac{\partial^{2} h}{\partial e^{2}}=24\right)$, combine this with the knowledge that no real solution exists for which $h(e)=0$ 
and thus we know $h$ is strictly positive. Therefore $k_{1}(e)$ is strictly convex and positive over the range of feasible values of $e$. It follows that there is a unique $e$ that minimizes $k_{1}(e), e=v / 4$ which is $k_{1}^{f, d}$. It follows that for fixed $v, N, k_{2}$, and feasible $e$ (positive $e$ and positive $v-2 e$ ) any $e: e \neq v / 4 \Rightarrow k_{1}>k_{1}^{f, d}$

\section{DELEGATION IN THE PRESENCE OF INFORMATION ASYMMETRY}

Let $N_{\min }$ be the minimum combined capability for which the VP seeks to pursue the initiative.

i) If the functional managers realize a combined capability of

$$
\tilde{N}= \begin{cases}N_{\text {min }} & \text { then } e^{a, d}=\frac{v}{4} \\ N>N_{\text {min }} & \text { then } e^{f b}(N)<e^{a, d}(N)<\frac{v}{4}\end{cases}
$$

ii) If $N_{\min }=h h$ then $e^{a, d, h h}=e^{f, d}(N=h h)$.

iii) For $N_{\text {min }}<h h$ the set of feasible initiatives $\mathcal{P}^{a, d}\left(N_{\text {min }}\right) \subset \mathcal{P}^{a, d, N_{\text {min }}}$.

iv) For $N_{\min }<h h$ there exists a threshold $\hat{\delta}\left(N_{\min }\right)$ such that only if $\delta<\hat{\delta}\left(N_{\min }\right)$ will a sufficiently low $V$ prompt the VP to choose $k 1>\frac{k_{2}}{1+2 k_{2}}$, otherwise $k 1 \leq \frac{k_{2}}{1+2 k_{2}}$.

Proof of Theorem 2. To simplify the exposition, we note the substitutability of $\eta$ and $V$ obtained in prior results. Thus, to simplify the exposition of the proofs ever so slightly, we normalize $\mu=1$ (the proofs hold for $\mu \neq 1$ ). When the realized capabilities $\tilde{N}=N_{\text {min }}$ the effort reverts to Theorem 1, where $e^{a, d}\left(N_{\min }\right)=e^{f, d}\left(N=N_{\min }\right)$. However, for $N>N_{\min }$ we need to evaluate the managers' FOC. Doing so, we find that the managers effort must satisfy the implicit equation $G^{a, d, N}=2 N\left(e^{3} N+3 e-V\right)+\left(e^{2} N-1\right)(2 e-V) N_{\min }=0$. We can implicitly differentiate the effort with respect to $N$ to find $\frac{\partial e^{a, d}}{\partial N}=\frac{-4 e^{3} N+e^{2}(V-2 e) N_{\min }-6 e+2 V}{N_{\min }\left(6 e^{2} N-2 e N V-2\right)+6 N\left(e^{2} N+1\right)}<0$.

The set of feasible initiatives is defined by finding $k_{1}$ such that the $N_{\text {min }}$ managers' PC is binding and $u_{f}=0$ :

When $N_{\min }=\ell \ell=(1-\delta)^{2}$ the managers' PC is binding if $k_{1}=\frac{2 k_{2}}{\left(1-\delta^{2}\right) e^{a, d}\left(V-2 e^{a, d}\right)}$ and since $e^{a, d \ell \ell}=$

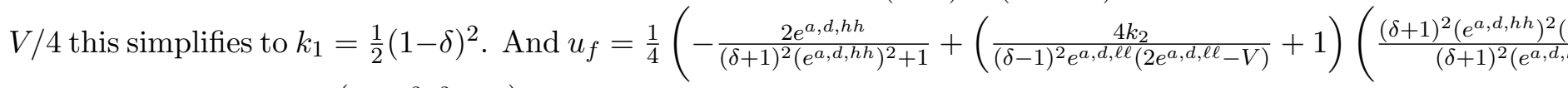
so that $u_{f}=0$ when $\frac{2\left((1-\delta)^{2} L^{2}-2 k_{2}\right)}{(1-\delta)^{2} L}$. So that $u_{f}\left(N_{\min }=\ell \ell\right)=0$ when $V=\frac{4 \sqrt{2 k_{2}}}{(1-\delta)^{2}}$. Likewise, $u_{f}\left(N_{\min }=\ell h\right)=0$ when $V=\frac{4 \sqrt{2 k_{2}}}{1-\delta^{2}} \cdot / /$ We then evaluate the incentive $k_{1}$ at the boundary of the feasible set, and find that $k_{1}^{a, d, \ell \ell}=\frac{1}{2}(1-\delta)^{2}$. Thus, at the boundary of the feasible set $k_{1}^{a, d, \ell \ell}>\frac{k_{2}}{1+2 k_{2}}$ 
for all $k_{2}$ if $\delta \leq \frac{1}{2}(2-\sqrt{2})$, otherwise for $\delta>\frac{1}{2}(2-\sqrt{2})$ if $k_{2}<\frac{(1-\delta)^{2}}{2 \delta(2-\delta)}$ it implies $k_{1}^{a, d, \ell \ell}>\frac{k_{2}}{1+2 k_{2}}$. We can repeat this same procedure for $N_{\min }=\ell h$ to find $k_{1}^{a, d, \ell h}>\frac{k_{2}}{1+2 k_{2}}$ for all $k_{2}$ if $\delta \leq \frac{1}{\sqrt{2}}$, otherwise for $\delta>\frac{1}{\sqrt{2}}$ if $k_{2}<\frac{(1-\delta)^{2}}{2 \delta^{2}}$ it implies $k_{1}^{a, d, \ell \ell}>\frac{k_{2}}{1+2 k_{2}}$

Centralized Decision Rights in the PRESEnce of information ASymmetry

Proof of Theorem 2. Follows directly from substituting the minimum viable initiative under delegated decision rights $\left(V_{\min }^{a, d}=\frac{4 \sqrt{2 k_{2}}}{N_{\min }}\right)$ into the centralized decision rights profit to show it is always negative. 


\section{References}

Abernathy, W.J., J. Utterback. 1978. Patterns of Industrial Innovation. Technology Review. $40-47$.

Aghion, P., J. Tirole. 1997. Formal and real authority in organizations. The Journal of Political Economy. 105(1), 1-29.

Akerlof, G. (1970). The market for lemons: Quality uncertainty and the market mechanism. Quarterly Journal of Economics. (89), 488-500.

Anderson, E. G., and Joglekar, N. R. (2005). A hierarchical product development planning framework. Production and Operations Management, 14(3), 344-361.

Bhattacharya, S. and D. Mookherjee. (1986). Portfolio Choice in Research and Development. The Rand Journal of Economics. 17(4), 594.

Blindenbach-Driessen, F. (2015). The (In) Effectiveness of Cross-Functional Innovation Teams: The Moderating Role of Organizational Context. IEEE Transactions on Engineering Management, 62(1), 29-38.

Bower, J. (1970) Managing the Resource Allocation Process: A Study of Corporate Planning and Investment. Harvard Business School Press. Boston, MA.

Bower, J. L., and Gilbert, C. G. (2005). From resource allocation to strategy. Oxford University Press.

Brady, D. (2005). The Immelt Revolution; He's turning GE's culture upside down, demanding far more risk and innovation. BusinessWeek 3926(64)

Chao, R. and S. Kavadias (2008). A Theoretical Framework for Managing the NPD Portfolio: When and How to Use Strategic Buckets. Management Science. 54 (5)

Chao, R., S. Kavadias and C. Gaimon (2009). Revenue Driven Resource Allocation: Funding Authority, Incentives and NPD Portfolio Management. Forthcoming in Management Science.

Che, Y. and S. Yoo. (2001). Optimal incentives in teams. American Economic Review. 91 (3)

Economist. (2006). The problem with solid engineering - Germany's export champions. The Economist. May

Farson, R. and R. Keyes. (2002). The Failure Tolerant Leader. Harvard Business Review, 80(8), 64-71. 
Fox, G. E., N.R. Baker, and J.L. Bryant. (1984). Economic Models for R and D Project Selection in the Presence of Project Interactions. Management Science. 30 (7), 890-904.

Fudenberg, D., J. Tirole. (1992). Game Theory. MIT Press, Cambridge, MA.

Garnier, J.P., (2008). Rebuilding the R\&D engine in big pharma. Harvard Business Review, 86(5), pp.68-70.

Gibbons, R. (2005). Incentives Between Firms (and Within). Management Science 51: 2-17 (Sections 1-4).

Govindarajan, V. (2000). Nucor Corporation (A). Tuck School of Business at Dartmouth Case Study.

Grossman, S. and O. Hart. (1983). An Analysis of the Principal-Agent Problem. Econometrica. $51: 7-45$.

Hamm, S. (2009). In Depth Is Silicon Valley Losing Its Magic? A road trip finds risk aversion, short-term thinking, and a few bold ideas. BusinessWeek 4115(28)

Iyer, A.V., L.B. Schwarz and S.A. Zenios. (2005). A Principal-Agent Model for Product Specification and Production. Management Science, 51(1), 106-119.

Hauser, J. (1998). Research, development and engineering metrics. Management Science 44(12) 1670-1689.

Hauser, J. and F. Zettelmeyer. (1997). Metrics to evaluate R,D\&E. Research Technology Management 40(4) 32-38.

Hermalin, B. E. (2013). Leadership and Corporate Culture. The Handbook of Organizational Economics, 432 .

Holmstrom, B. (1982). Moral Hazard in Teams. Bell Journal of Economics. 13: 324-340.

Hutchison-Krupat, J., and Chao, R. O. (2014). Tolerance for failure and incentives for collaborative innovation. Production and Operations Management, 23(8), 1265-1285.

Hutchison-Krupat, J., and Kavadias, S. (2014). Strategic resource allocation: Top-down, bottom-up, and the value of strategic buckets. Management Science, 61(2), 391-412.

Hutchison-Krupat (2017). Communication, Incentives, and the Execution of a Strategic Initiative. Management Science. Forthcoming.

Hutchison-Krupat, J., and Kavadias, S. (2017). Task interdependence, uncertainty, and incentive metrics for team projects. Darden School of Business Working Paper. 
Kavadias, S. and R. Chao. (2007). Resource Allocation and NPD Portfolio Management. in Loch, C.H., S. Kavadias, eds., Handbook of New Product Development Management. Butterworth Heinemann/Elsevier, Amsterdam, 315-343.

Kim, Y. H., Sting, F. J., and Loch, C. H. (2014). Top-down, bottom-up, or both? Toward an integrative perspective on operations strategy formation. Journal of Operations Management. $32(7), 462-474$.

Loch C.H. and J. Mihm. (1996). American Switching Systems. INSEAD Case Study.

Loch, C.H. and S. Tapper. (2002). Implementing a strategy-driven performance measurement system for an applied research group. The Journal of Product Innovation Management. 19(3), 185-198.

Loch, C.H. and S. Kavadias. (2011). Implementing Strategy Through Projects. in Morris, P.J., J. Pinto

Manso, G., (2011). Motivating innovation. The Journal of Finance, 66(5), pp.1823-1860.

Markowitz, H. (1952). Portfolio Selection. The Journal of Finance.7 (1)

Mihm, J., C. H. Loch and A. Huchzermeier. (2003). Problem Solving Oscillations in Complex Engineering Projects. Management Science 49(6) 733-750.

Mihm, J., (2010). Incentives in new product development projects and the role of target costing. Management Science, 56(8), pp.1324-1344.

Poole, M. S., Van de Ven, A. (Eds). (2004). Handbook of organizational change and innovation. New York: Oxford University Press.

Schein, E. H. (2010) Organizational Culture and Leadership. 4th Edition Jossey-Bass Publishers, San Francisco, CA.

Schlapp, J., Oraiopoulos, N., and Mak, V. (2015). Resource allocation decisions under imperfect evaluation and organizational dynamics. Management Science. 61(9), 2139-2159.

Siemsen, E. (2008). The Hidden Perils of Career Concerns in R\&D Organizations. Management Science. $54(5)$

Sosa, M. E., Eppinger, S. D., Pich, M., McKendrick, D. G., and Stout, S. K. (2002). Factors that influence technical communication in distributed product development: an empirical study in the telecommunications industry. IEEE transactions on engineering management, 49(1), $45-58$. 
Sosa M., S. D. Eppinger and C.M Rowles (2004). The Misalignment of Product Architecture and Organizational Structure in Complex Product Development. Management Science. 50 (12), 1674-1689.

Tatikonda, M. V., and Rosenthal, S. R. (2000). Technology novelty, project complexity, and product development project execution success: a deeper look at task uncertainty in product innovation. IEEE Transactions on engineering management, 47(1), 74-87.

Thomke, S. (2000). IDEO Product Development. Harvard Business School Case Study, 9-600-143 Van den Steen, E. (2006). On the Origin of Shared Beliefs (and Corporate Culture). Working Paper 